\title{
RAZVOJ SLOVENSKE VOJSKE V DRUGEM DVAJSETLETJU NJENEGA OBSTOJA
}

\section{DEVELOPMENT OF THE SLOVENIAN ARMED FORCES IN THE FOLLOWING TWENTY YEARS}

Professional article

Povzetek Posodobljeni strateški politični in usmerjevalno-planski dokumenti Republike Slovenije (RS so sorazmerno dobra podlaga za nadaljnji razvoj obrambnega sistema in transformacijo Slovenske vojske (SV. V dvajsetih letih je bilo narejenega veliko, predvsem SV je glede na čas doživela najbolj dramatične spremembe. Uresničevanje novih strategij je treba nadaljevati in preseči trenutno ambivalentnost. Zastavljene cilje je mogoče doseči s krepitvijo konsistentne obrambne politike in načrtovanja, podprtih z ustreznimi viri. Obrambni sistem in SV bosta morala biti vedno bolj prilagodljiva za različne naloge in potrebe, zato utegne modularni pristop organiziranja prispevati k njuni učinkovitosti. Pri definiranju organizacije SV je treba osvojiti celovit pristop. SV bo še naprej organizirana kot enovita vojska, brez delitve na zvrsti. Glede na prostor in potrebe usklajenega načrtovanja sil in delovanja v Natu pa bo upoštevala delitev sil znotraj zavezništva za opravljanje nalog na kopnem, v zračnem prostoru in na morju. Njena organizacija bo temeljila na delitvi na bojne enote, enote bojne podpore, enote za zagotovitev bojnega delovanja in enote za podporo poveljevanju. Organizacijska struktura SV bo leta 2025 zagotavljala možnost modularnega sestavljanja sil za izvajanje nalog ob največji mogoči racionalizaciji poveljniške strukture. Pri organiziranju sil bodo upoštevana predvsem vojaškostrokovna načela in načela učinkovitosti ob upoštevanju načel gospodarnosti. Obseg Slovenske vojske, pa tudi njeno konfiguracijo in značaj, bodo določali različni, med seboj prepleteni dejavniki, kot so demografski, ekonomski, politični in drugi. Celovit pristop pri dodeljevanju nalog znotraj države in celostna uporaba virov pri upravljanju in reševanju varnostnih izzivov pa sta ključnega pomena. Slovenija bo v prihodnosti samozavestnejša v premisleku o svoji organiziranosti, delovanju, dojemanju priložnosti in uresničitvi svojih ambicij.

Ključne Slovenska vojska, obrambne zmogljivosti, mednarodne operacije in misije, besede varnostno okolje, uporabnost sil, modularnost, celostni pristop, transformacija. 
Abstract The updated strategic policy as well as steering and planning documents of the Republic of Slovenia represent a relatively good platform for further development of the defence system and the transformation of the Slovenian Armed Forces (SAF). A lot has been achieved in the past twenty years. The Slovenian Armed Forces in particular have faced dramatic changes considering the period in which they were implemented. Slovenia should continue to implement new strategies and try to overcome the temporary ambivalence. The planned goals can be achieved by reinforcing consistent defence policy and planning, supported by appropriate resources. The Defence System and the SAF in particular will have to be increasingly flexible when it comes to different assignments and needs, and perhaps the modular approach to its organization will contribute to its efficiency. A comprehensive approach will have to be taken when defining SAF structure. The SAF will continue to be organized as a unified force, without branches. However, because of coordinated force planning and work within NATO, it will respect the division of forces for the performance of tasks on land, in the air and at sea. The organization of the SAF will be based on Combat, Combat Support, Combat Service Support and Command and Control Support units. The 2025 SAF structure will allow for modular force generation for the performance of tasks, taking into account the highest possible rationalization of the command structure. The organisation of forces will mainly follow the principles of the military profession, efficiency and economy of effort. The size of the SAF as well as its configuration and character will be determined by several interrelated factors, such as demographic, political, economic factors, etc. Nevertheless, a comprehensive approach and comprehensive use of resources in managing and dealing with the security risks will be crucial. In the future, Slovenia will demonstrate more self-confidence when it comes to considering the organization of its defence, performance, understanding of opportunities and realisation of the existing and growing ambitions.

Key words Slovenian Armed Forces, defence capabilities, defence, international operations and missions, security environment, usability of forces, modularity, comprehensive approach, transformation.

UVOD Pri razmišljanju o prihodnosti Slovenske vojske moramo črpati iz naučenega in izkušenj, ki smo jih pridobili $\mathrm{v}$ dosedanjem razvoju. Razvoj SV moramo razumeti kot veliko notranjo transformacijo v sorazmerno kratkem času, nastalo iz Teritorialne obrambe in formacij rezervne sestave, namenjenih podpori rednim oboroženim silam, v poklicno vojsko, sposobno delovanja v najzahtevnejših operacijah Severnoatlantskega zavezništva, katerega del je Slovenija že sedem let. Pri tem se moramo zavedati omejitev, ki se kažejo predvsem na področju finančnih, materialnih in kadrovskih virov. Modro ravnanje z njimi mora zagotoviti nadaljnji razvoj vojaških zmogljivosti, njihove pripravljenosti in uporabnosti. Pred nedavnim je Slovenija s posodobljeno Resolucijo o nacionalni varnosti (ReSNV) in novo Resolucijo o splošnem dolgoročnem programu razvoja in opremljanja Slovenske vojske do leta 2025 (ReSDPRO 2025), kmalu pa bo sprejeta tudi nova obrambna 
strategija, začrtala novo vizijo razvoja obrambnih sil in obrambnega sistema, predvsem SV. Nato je posodobljene strateške usmeritve pozdravil. Na vrsti je njihovo uresničevanje in preseganje trenutne ambivalentnosti, ki bi jo lahko opisali kot stopicanje na mestu, nazadovanje, spogledovanje s preživetimi vzorci in preveč ukvarjanja s seboj.

V tem članku želimo predvsem predstaviti pogled naprej, torej smer razvoja Slovenske vojske, ki jo omogoča ReSDPRO, skušati razložiti smisel take smeri in hkrati izpostaviti nekaj preteklih in aktualnih težav, ki lahko odločilno vplivajo na razvoj.

\section{PRVO DVAJSETLETJE}

SV je $\mathrm{v}$ zadnjih letih prehodila dolgo in naporno pot tranzicije, reorganizacije in transformacije. Teritorialna obramba (TO), ki je bila organizirana in usposobljena za delovanje na pomožnih smereh ob podpori manevrskih sil (takratne Jugoslovanske ljudske armade - JLA) za nadzor ozemlja in delovanje na začasno zasedenem ozemlju, je leta 1991 ob osamosvojitvi štela približno 36.000 pripadnikov, takoj zatem pa je narasla celo na 76.000. Pred prevzemom naborniškega sistema in ustanovitvijo prvih učnih centrov je seveda častno mesto treba nameniti Manevrski strukturi narodne zaščite, ki je bila leta 1990 vez med politično oblastjo, ustanovljenimi manevrskimi silami in TO, iz katere so med drugimi izhajali njeni pripadniki.

V tistem času je bilo treba mobilizirati vse sile, njihova zagotovitev pa je bila odvisna od civilne obrambe, prav tako tudi njihova premičnost in oprema, saj so materialna sredstva in infrastruktura opredeljeni v zakonu o materialni dolžnosti.

Sistem poveljevanja in kontrole se je opiral predvsem na prostorsko strukturo, temu primerno pa so bile oblikovane tudi enote, večinoma sestavljene iz odredov vodne in četne sestave. Preimenovanje TO v SV leta 1994 je bilo tudi vsebinsko, ker je bil večji poudarek namenjen manevrskim silam. Kljub temu da je bila podlaga poveljevanja in kontrole (PINK) še vedno prostorsko orientirana, so se začeli oblikovati bataljoni in lahke pehotne brigade, popolnjeni z naborniki in rezervno sestavo. Težišče bataljonskih formacij pa je bilo na razvoju preostalih rodov in zametkov zvrsti.

Vstop v Partnerstvo za mir (PzM) in pozneje sodelovanje v prvih mednarodnih operacijah in na misijah (MOM) sta dajala nov zagon ter predvsem prinašala nova spoznanja v SV. Aktivno sodelovanje znotraj zavezniških programov načrtovanja in pregleda obrambe (PARP) ter Akcijskega načrta za članstvo (MAP) pa je dodalo še novo pomembno dimenzijo, razvoj povezljivih zmogljivosti. Značilnost tega obdobja je bil poskus formiranja bataljona za mednarodne operacije, ki pa se je dokaj neuspešno potegoval za prednost pri virih za modernizacijo, predvsem kadrovskih in finančnih. Do ustrezne Natove certifikacije je potreboval deset let razvoja. 
Spoznavanje prave kompleksnosti razvoja vojaške organizacije, zagotavljanja ustreznih virov in učinkovitega civilnega nadzora sovpada z nekaterimi prelomnimi trenutki in strateškimi odločitvami v razvoju SV. Ob prvi zavrnitvi za vstop v zavezništvo je leta 1997 politika dokončno spoznala, da je treba investirati več. In povabilo za vstop v Nato je končno prišlo v Pragi, novembra 2002. Slovenija je postala polnopravna članica marca 2004, maja istega leta smo postali tudi članica EU. V tem času je bilo sprejetih več pomembnih odločitev, in sicer prva ReSDPRO SV, politična odločitev za prehod na poklicno popolnjevanje vojske in opustitev naborništva, za prehod s partnerskih ciljev na cilje sil Nata, zagon projekta profesionalizacije SV (PROVOJ) in oblikovanje prvega srednjeročnega programa obrambnega sistema (SOPR).

Pred temi odločitvami je imela SV že načrtovano reorganizacijo na obseg 24.000 pripadnikov, ki se je ob odločitvi za poklicno vojsko skoraj prepolovil. Poudariti je treba, da so bili za sprejem politične odločitve porabljeni samo trije meseci. Večina politik v državah zavezništva je takšno odločitev tehtala in proučevala daljše obdobje in prehod raztegnila na različno dolga, večletna obdobja. Naše prehodno obdobje je bilo zaznamovano z istočasnim obstojem tako obvezne kot na novo ustanovljene prostovoljne rezerve. Določil se je tudi ciljni obseg 14.000, ki naj bi ga dosegli leta 2010, ko naj bi se obvezna rezervna sestava ukinila.

Če izpustimo začetne ambicije korpusne formacije oboroženih sil, je bila ta struktura vedno bolj podobna zahtevanim in primerljivim strukturam zavezništva, na čigar kolektivno obrambo se je RS tudi začela naslanjati ob hkratnem povečevanju sil $\mathrm{v}$ MOM. Po začetku sodelovanja v operaciji OZN na Cipru so slednje kulminirale z napotitvijo bataljona na Kosovo leta 2007 in danes delujejo na treh celinah (Evropa, Azija oz. Bližnji vzhod ter Afrika), pod okriljem OZN, EU in Nata. Danes SV deluje $\mathrm{v}$ šestih operacijah različnega tipa in intenzivnosti v devetih državah $(2 \mathrm{x}$ OZN, 2 x EU in $2 \mathrm{x}$ Nato).

Z odločitvijo vlade o določitvi ciljnega obsega SV na 10.000 pripadnikov ob hkratnem pregledu obrambnega resorja se je leta 2009 začelo novo obdobje za SV, v katerem je bilo treba spremeniti in prilagoditi krovne strateške dokumente ter začrtati pot naprej. SV je tako iz naborniške vojske prerasla v poklicno, majhno in deloma sodobno opremljeno silo, ki je sposobna uresničevati poslanstvo in opravljati naloge, predpisane z zakonom ter drugimi podzakonskimi predpisi in akti, tako doma kot znotraj zavezništva. Brez večjega tveganja lahko sklepamo, da je uveljavljanje nacionalnih ciljev sil, dogovorjenih z Natom, v Sloveniji prispevalo predvsem k uporabnejšim in racionalnejšim vojaškim zmogljivostim. Tako sta Slovenija in zavezništvo dobila potrditev, da je zastavljene cilje mogoče doseči s konsistentno obrambno politiko in načrtovanjem, ki morata biti podprta z ustreznimi viri (Šavc, 2009). 


\section{RAZLIČNI POGLEDI NA OBRAMBNO SPOSOBNOST SLOVENIJE OB DVAJSETI OBLETNICI OSAMOSVOJITVE}

Še pred dvajseto obletnico osamosvojitve so se v Sloveniji ponovno pojavile pobude o ukinitvi SV. Skoraj nemudoma je to kampanjo ustavil Državni zbor, ki je med poskusom velike polemike s prepričljivo dvotretjinsko večino potrdil novo ReSNV. $\mathrm{V}$ tej strategiji, čeprav ji posamezni kritiki ne priznavajo sodobnosti, je pa toliko bolj sodobna, kolikor bolj je Slovenija zaostala za najnovejšimi tokovi razvoja varnostnega sektorja, so postavljene logične, smiselne, stvarne in nujne politične usmeritve razvoja nacionalnovarnostnega in obrambnega sistema RS v prihodnjem obdobju. Dobro leto po sprejetju najvišjega strateško-usmerjevalnega dokumenta države lahko žal ugotovimo, da ni vzbudil velikega zanimanja in da se ne uveljavlja. Obrambni resor pa ga upošteva, zato zadeve v svoji pristojnosti, z vsemi težavami vred, počasi, a vztrajno razvija naprej. Pri tem je treba poudariti, da je vlada do zdaj sprejela le dva srednjeročna programa obrambe, zadnjega leta 2006 za obdobje 2007-2012. Manjkata pa leta 2008 pripravljeni SOPR 2009-2014 in leta 2010 pripravljeni SOPR 2011-2016, ki naj bi bil sprejet letos.

Nobeni državi, pa naj bo majhna ali velika, ni lahko upravljati raznolikosti, potrebnih za podporo transformacijskim in modernizacijskim naporom nacionalnih prednostnih nalog ter Nata, EU ali drugih zavez. Verjamemo da je bila odločnost, da bi Slovenija imela vse, kar imajo veliki, napačna (Humar, 2009, str. 68) in da smo predolgo vztrajali na zaupanju sami sebi (Šavc, 2009, str. 44).

Nova obrambna strategija bo v kratkem predložena Vladi RS v sprejem, še prej pa je bilo zaradi nuje treba sprejeti novo Resolucijo o splošnem dolgoročnem programu razvoja in opremljanja SV do leta 2025 (ReSDPRO 2025), ki je bila v osnutku predmet polemik tako znotraj obrambnega resorja kot $\mathrm{v}$ politični in ne nazadnje tudi javni sferi. Pokazalo se je, da imajo kritiki skupni imenovalec, in sicer, da se SV ne sme razvijati $\mathrm{v}$ smer prave bojne sposobnosti in da ne sme sodelovati v mednarodnih operacijah in na misijah višje bojne intenzivnosti. Ni naključje, da so bili ti kritiki pred sedmimi leti večinoma tudi goreči nasprotniki članstvu »dežele« v Natu. Interes po zaustavitvi razvoja, modernizacije in angažiranja SV v sodobnem političnem življenju RS je legitimen, čeprav ga marginalizirata oba strateška usmerjevalna dokumenta, sprejeta pred nedavnim v Državnem zboru. Slovenska javnost ni, in kar se tiče obrambe države ne more biti, naivna, saj se še živo spomni izkušnje osamosvojitve, da ne posegamo še bolj v zgodovino. Nanjo nas spomni vsaka kriza, ki izbruhne na bolj ali manj oddaljenih območjih sveta, in te se zadnje čase kar vrstijo. Sploh pa zelo ceni resnico in dejstva, mnogo bolj kot demagoške primerjave, kaj vse bi si lahko privoščili namesto dragih vojaških investicij. Tudi ko se igra s čustvi državljanov, njihov razum, pogum in ponos popolnoma prevladajo nad vzorcem sebičnosti.

Obrambni resor bo moral postati bolj prilagodljiv in dinamičen tudi z upravljavskega vidika (krizni časi to samo potrjujejo), predvsem zaradi nenehne potrebe po 
prilagajanju nikoli končanih reform, domiselnosti in inovativnosti. Ker finančnih virov za obrambo nikoli ni bilo in ne bo v izobilju, bo treba določati, kaj ima $\mathrm{v}$ resnici prednost med nacionalnimi in zavezniškimi interesi (kmalu v Sloveniji med tema dvema kategorijama ne bo večjih razlik) in bo torej hkrati dodana vrednost obrambni moči ter verodostojnosti Slovenije v mednarodni skupnosti.

\section{ZNAČAJ OBRAMBNIH ZMOGLJIVOSTI V PRIHODNOSTI}

Združene oborožene sile (zvrstno), ki bodo v večnacionalnem smislu tudi povezljive in integrirane, bodo morale biti sposobne delovanja ne samo na varnostnem področju, temveč tudi na področju obvladovanja mehanizmov pri gradnji državnih institucij, razvoja, širšega uresničevanja političnih strategij, skladno z načrtovanimi smermi operacij, ter vsakodnevnega in neprekinjenega urjenja vojaških sil, preden bodo uporabljene. Morale bodo biti sposobne delovati v različnih omrežjih in med njimi (ne zgolj tehnološkimi, temveč tudi upravnimi, socialnimi ipd.). Oborožene sile bodo vse bolj integrirane, saj majhne in srednje države ne morejo vzdrževati celovitih konvencionalnih zmogljivosti. Tehnologija narekuje hitrost in investicije se podvojijo na deset do dvajset let, zato je treba zmanjšati številčnost, a povečati kakovost in učinkovitost. Pri tem pridemo do problema ustreznega »designa« oboroženih sil, saj zmanjšanje ne sme ogroziti minimalne nacionalne strukture, ki v organizacijskem smislu omogoča njihovo delovanje in eksistenco.

\subsection{Modularnost, celovit pristop, manj nacionalno in bolj večnacionalno}

Vzdrževanje konvencionalnih sil zahteva usklajevanje obrambe in varnosti ter pravzaprav integrirano večdržavno strukturo (tudi s sosedi in zaveznicami), kar pa $\mathrm{v}$ ospredje postavlja politična vprašanja, kot je na primer nacionalna suverenost. Skupne nabave in logistika, usposabljanje in urjenje, obrambno načrtovanje, politična volja, ne samo pragmatični interes, deliti svoje zmogljivosti z drugimi po eni ali združevati jih z drugimi po drugi strani v okviru večnacionalnih projektov, zahtevajo brezpogojno medsebojno zaupanje. Poleg tega pa se postavlja v ospredje paradigma oborožitvene industrije, predvsem z vidika nacionalne konkurenčnosti. To sicer v Sloveniji na nacionalni ravni ni prisotno, kljub temu pa ima industrija večjih evropskih držav na večnacionalne projekte manjših držav bistven vpliv, posredno torej tudi na interese Slovenije.

Modularnost utegne postati ena poglavitnih značilnosti oboroženih sil. Obrambni ministri skandinavskih držav so podpisali obrambno sodelovanje na področjih raziskav in razvoja kopenske vojske, mornarice in letalstva, človeških virov, logistike, urjenja in usposabljanja ter koncept razvoja in eksperimentiranja (Concept of Development and experimentation - CD\&E). (Johansson, 2008) To je primer, ki je v ospredju pozornosti tako $\mathrm{v}$ EU kot v Natu in iz katerega se je mogoče veliko naučiti na strokovni in politični ravni. Drugi primer so dve nevtralni državi (Finska in Švedska), članici Evropske unije ter njene skupne varnostne in obrambne politike (SVOP), in dve članici Nata (Norveška in Danska), ki imata vsaka zase poseben 
odnos in status v SVOP. Zadnji primer pa je skupni nastop dveh velikih zgodovinskih tekmic, Francije in Velike Britanije, ki le še potrjuje prepričanje, da si srednje in majhne države preprosto ne morejo več samostojno privoščiti vseh sodobnih konvencionalnih zmogljivosti.

\subsection{Sposobnost Slovenske vojske za izvajanje nalog v sodobnem varnostnem okolju}

S spremenjenim strateškim okoljem se spreminja tudi spekter vojaških nalog SV. V miru bodo prevladovale različne oblike urjenja in usposabljanja, pomoč ob naravnih in drugih nesrečah, sodelovanje v operacijah kriznega odzivanja oziroma mednarodnih operacijah in na misijah ter naloge, povezane s podporo drugim državnim organom in organizacijam pri zagotavljanju varnosti države in državljanov RS. Seznam vojaških nalog v izrednih razmerah ali vojni bo širši, povečani bosta nepredvidljivost in raznovrstnost operativnih nalog. Na seznamu bodo tako omejeni spopadi, omejeni konvencionalni konflikti in regionalna konvencionalna vojna.

Sodobno tehnološko-informacijsko okolje narekuje tudi prilagajanje oboroženih sil in redefinira naravo oziroma metode vojskovanja. Vojskovališča so postala digitalizirana, oborožitveni sistemi pa so vedno bolj avtomatizirani. V ospredju je razvoj sodobnih, informacijsko podprtih oborožitvenih sistemov ter sistemov poveljevanja in kontrole.

Vpadi v informacijske sisteme, blokada delovanja celotnih sistemov, pregledovanje, spreminjanje ali uničevanje podatkov ter posredovanje netočnih, napačnih ali zavajajočih informacij so nove oblike groženj, ki jih omogoča (zlo)raba informacijskih sistemov.

Poleg treh klasičnih dimenzij spopadov (kopno, morje, zrak) in kibernetičnega prostora se vse bolj uveljavlja tudi tretje območje vojskovanja, vesolje. Tudi vse sedanje združene operacije potekajo ob uporabi sredstev v vesolju.

Narava usposobljenosti in značaj enot SV morata dosegati izvrstnost in dovršenost v bojevanju na gozdnatem zemljišču, v sredogorju in z delovanjem manjših skupin tudi v naseljenih mestih. Takšna je Slovenija. Glavna načela (bojnega) delovanja oboroženih sil RS bodo $\mathrm{v}$ prihodnje prilagojena klasičnemu okolju obrambe naše države, ki mu moramo prilagoditi zmogljivosti za preživetje oziroma sposobnost za obrambo lastnih sil, raznovrstnost oziroma sposobnost za opravljanje čim več različnih nalog, vzdržljivost oziroma sposobnost za samostojno in učinkovito opravljanje nalog za hitro posredovanje oziroma sposobnost za čim hitrejši odziv na nastalo krizo, trdoživost oziroma odpornost proti različnim vrstam napadov ter sposobnosti za dolgoročno delovanje in opravljanje različnih nalog, za prihod na območje krize v čim krajšem času in za čimprejšnje (bojno) delovanje.

Priprave na (bojno) delovanje oboroženih sil prihodnosti bodo zahtevale temeljite spremembe $\mathrm{v}$ urjenju, usposabljanju vodstva, razvoju konceptov in doktrin ter 
razvoju in uvajanju novih (bojnih) sredstev. Sodobne oborožene sile bodo sposobne delovati v zelo različnih vremenskih razmerah in na zelo različnih terenih, na katerih lahko nasprotnik uporablja konvencionalne in nekonvencionalne oblike bojevanja. Kot metoda nekonvencionalnega bojevanja se izpostavljata asimetričnost in njen skrajni pojav - terorizem. Veča se tudi verjetnost uporabe orožja za množično uničevanje. Namesto konvencionalnega bojevanja sile proti sili se pojavlja nekonvencionalno, nesimetrično bojevanje, bojevanje sistema proti sistemu oziroma proti tako imenovanim hibridnim grožnjam.

Poglavitna načela delovanja oboroženih sil prihodnosti bodo pravočasno zaznati položaje in namere nasprotnika ter prevzeti pobudo in pravočasno ter učinkovito delovati proti njemu. Nenehno bo treba spreminjati način delovanja in s tem nasprotniku preprečiti, da bi se prilagodil razmeram. Upoštevanje teh načel je bistveno, da bi se izognili poskusom vsiljevanja strategije izčrpavanja in velikim žrtvam.

Enote SV bodo morale biti prilagodljive za različne naloge in potrebe, sposobne skupnega in sočasnega delovanja $\mathrm{z}$ drugimi enotami ter povezane $\mathrm{v}$ sodoben informacijski sistem. To jim bo omogočilo boljše védenje o dogajanju na bojišču ter simultano delovanje proti nasprotniku. $\mathrm{V}$ prihodnosti bodo morale biti sposobne delovati integrirano $\mathrm{v}$ mednarodnem okolju in omrežjih, ob tem pa biti v dogovorjenem obsegu sposobne delovati tudi samostojno. Modularni pristop organiziranosti bo prispeval predvsem k prožnejšemu odzivanju na dogodke in izvajanju nalog.

\section{OBSEG IN STRUKTURA SLOVENSKE VOJSKE}

Slovenija bo imela takšna obseg in strukturo vojske, ki bosta omogočala izpolnjevanje njenih zakonsko določenih nalog. Sistem vojaškega izobraževanja in usposabljanja, skupaj z delovanjem enot in poveljstev v strukturah zavezništva, mora zagotoviti razumevanje in sposobnost vključevanja $\mathrm{v}$ mednarodne medzvrstne operacije. $Z$ osnovnima konfiguracijo in konceptom moramo osvojiti celovit pristop $\mathrm{k}$ definiranju organizacije.

SV bo še naprej organizirana kot enovita vojska, brez delitve na zvrsti. Glede na prostor in potrebe usklajenega načrtovanja sil in delovanja $\mathrm{v}$ Natu bo upoštevala delitev sil znotraj zavezništva za izvajanje nalog na kopnem, v zračnem prostoru in na morju.

V sodelovanju z zavezniki bo razvijala zmogljivosti za učinkovito izvajanje vseh vojaških nalog na kopnem. Izvajanje kopenskih operacij zahteva sile, ki so premestljive, premične, z zadovoljivima zaščito in ognjeno močjo, ustrezno opremljene in usposobljene. Zaradi tega se bo vojska organizirala v tako uravnotežene in sestavljene enote, ki bodo sposobne izvajati združeno bojevanje taktične ravni na ravni taktične skupine in taktične bojne skupine od čete do bataljona ali polka. Njena struktura bo omogočala premeščanje oziroma uporabo štirih taktičnih bojnih skupin, in sicer avtonomno na dveh ali treh različnih smereh, brez ognjene podpore višje 
ravni. Taktične bojne skupine SV bodo lahko integrirane v večnacionalno brigadno strukturo, izjemoma pa bo združena taktična enota brigadne ravni SV na domačem ozemlju sposobna izvajati vse kopenske operacije, verjetno (praviloma) v sestavi višje večnacionalne enote, da bo tako lahko sprejemala ognjeno in siceršnjo podporo zaveznikov. Sposobna bo z dodanimi elementi uporabljati bojne multiplikatorje sistema poveljevanja. Sistem vodenja in poveljevanja bo omogočal vključevanje v sodobne sisteme zavezništva, ob tem pa zagotavljal informacijsko premoč $\mathrm{z}$ združevanjem senzorjev in bojiščnih sistemov ter hkrati tudi podporo odločanju poveljnikov. Zagotovljena bo možnost integracije računalniško podprtega urjenja in delovanja na vseh ravneh.

Struktura SV bo zunaj območja države zagotavljala vzdrževanje taktičnih skupin (četnih ali bataljonskih) v rotaciji, za kar potrebuje najmanj tri bataljone ali polke. Poleg tega bo imela za zahteve zavezništva pripravljen okvir bataljona radiološko-biološko-kemične obrambe ali vsaj nekatere njegove dele ter nekatere druge manjše zmogljivosti, vendar v dogovorjenem časovnem zaporedju. Enote za zagotovitev delovanja bodo postavljene in opremljene za manevrsko bojevanje in evakuacijo posameznih elementov taktične skupine z ustrezno zaščito. Višje stopnje vzdrževanja bojne tehnike se bodo zagotavljale predvsem za enote za bojevanje in bojno podporo. Vse enote kopenske sestave bodo popolnjene tudi z rezervno sestavo ter sestavljene po modularnem načelu.

Težišče razvoja bo na bojnem delu kopenske vojske in njeni bojni podpori. Enote bodo usposobljene po enakih standardih za zagotovitev zaščite bokov, premikov in obrambo ključnih objektov. Zagotovljena bosta organizacija sprejema zavezniških enot na ozemlju RS ter nadomeščanje izgub v boju ali operaciji oziroma dopolnjevanje enot, če bo treba tudi s strateško rezervo. Te enote bodo poleg prostih zmogljivosti manevrskih sil glavna podpora sistemu varstva pred naravnimi in drugimi nesrečami oziroma sodelovanju z drugimi državnimi organi in javnimi ustanovami.

SV bo v sodelovanju z zavezniki zagotovila zmogljivosti za učinkovito delovanje v zračnem prostoru. Glede na mogoče grožnje iz zraka bo struktura sil zagotavljala razmere za hitro uresničitev odločitev za delovanje, sprejetih na politično-vojaški ravni, ne glede na način izvedbe. Elementi sistema bodo združljivi in bodo tako neposredno podpirali postopno integracijo v združen sistem razširjene zračne obrambe Nata. Samostojno bomo sposobni zaščititi taktične premične elemente in letališče.

Zagotovljena bosta taktični vertikalni manever čete na ozemlju Slovenije in podpora delovanju taktične bojne skupine v vseh oblikah delovanja v vlogi bojnega elementa ali bojne podpore. Zmogljivosti taktičnega vertikalnega manevra bodo v enem naletu omogočale taktični premik pehotne čete.

SV bo v sodelovanju z zavezniki skrbela tudi za obrambo in zaščito akvatorija. Z elementi podvodnega delovanja bo zagotavljala varovanje pomorskih poti in varen dostop do pristanišča Koper. Te zmogljivosti bodo, skupaj z zavezništvom, oblikovale 
podporo ofenzivnemu delovanju zavezništva $\mathrm{v}$ zaščiti oskrbovalnih pomorskih poti in vstopno sprejemno pomorsko točko sil zavezništva pri prečkanju slovenskega ozemlja in delovanju na njem. Obramba slovenskega akvatorija se bo izvajala tudi z večnamenskimi bojnimi sistemi s kopnega, s posebnim poudarkom na racionalizaciji in poenotenju bojnih sredstev. Te sile bodo v miru lahko z nekaterimi sredstvi in sistemi sodelovale $\mathrm{z}$ drugimi državnimi organi, saj bodo večinoma opravljale naloge, ki se sicer pripisujejo obalni straži.

Organizacijska struktura SV bo leta 2025 zagotavljala možnost modularnega sestavljanja sil za izvajanje nalog ob največji mogoči racionalizaciji poveljniške strukture. Pri organiziranju sil bodo upoštevana predvsem vojaškostrokovna načela in načela učinkovitosti ob upoštevanju načel gospodarnosti. Racionalnost sistema vodenja in poveljevanja lahko dosežemo z združitvijo, na primer operativno-strateške ravni poveljevanja. Usposabljanje in urjenje bosta še naprej upoštevali klasično delitev ravni vodenja vojskovanja. Težišče usposabljanja je treba usmeriti v združeno bojevanje in delovanje rodov, temeljni gradnik pa je četa.

Dvojnost zmogljivosti ob upoštevanju potreb sistema zaščite in reševanja je zelo pomembna in včasih premalo izpostavljena ter uporabljena prednost. Lahko bi bolj konkretizirali usluge prečiščevanja vode, proste transportne zmogljivosti, elemente RKBO in tudi možnost prevzema odgovornosti vodenja ob naravnih in drugih večjih nesrečah, ko so porabljene zmogljivosti sistema zaščite in reševanja ter drugih virov. $\mathrm{V}$ resnici je to del širše podpore drugim državnim organom in civilnemu okolju oziroma družbi in ne, kot v Sloveniji radi razumemo, samo posebna podpora sistemu varstva pred naravnimi in drugimi nesrečami.

Pri določanju obsega SV bi želeli izpostaviti dva dejavnika. Prvi je demografski oziroma kolikšen odstotek populacije, sposobne za delo, se lahko vključi v oborožene sile. V tesni povezavi s tem je tudi prepletenost civilne družbe in vojske. Drugi dejavnik je ekonomske in politične narave, tako njegov zunanji kot tudi notranji vidik. S tem so tesno povezani vprašanje politične ambicije vladajoče elite in stvarne zmožnosti oziroma naravne omejitve države za proaktivno udeležbo v procesih zagotavljanja stabilnosti in spopadanja z grožnjami svetovnemu miru in varnosti. Na to vplivajo tudi razmerja med zavezništvi in znotraj njih ter množica drugih političnih, ekonomskih ali varnostnih in vojaških elementov. Še vedno predvsem šteje, koliko si na kriznih območjih pripravljen tvegati s prisotnostjo svojih predstavnikov, torej civilnih funkcionalnih strokovnjakov, diplomatov in največkrat vojakov.

V kompleksnih mirovnih operacijah in na misijah je oborožena sila praviloma prevladujoč fizični dejavnik, a vseeno le eden izmed mnogih, ki jih ima na voljo politika (Mikuž, 2010, str. 49).

Notranji dejavnik predstavlja celovit vladni pristop pri dodeljevanju nalog znotraj države. Celostna uporaba virov pri upravljanju in reševanju izzivov je ključnega pomena, s čimer se bo Slovenija morala slej ko prej soočiti in resno začeti delati. 
Uravnoteženost med tema dvema dejavnikoma nakazuje smer oblikovanja strukture oboroženih sil, ki mora prednostno najti težišče, če želi biti učinkovita ob zadržanju sposobnosti delovanja na obeh ravneh. V Sloveniji so preveč izpostavljeni čustvena in psihološka vloga, determinirani na zgodovinski perspektivi in izkušnjah družbe, ter strahovi političnih elit pri konsistentnosti oblikovanja ciljnega stanja, značaja in nalog oboroženih sil.

Nekako namerno ne želimo povedati, kako velika bi morala biti ali bi lahko bila SV v prihodnosti, ker so odgovori na prej odprta vprašanja in polemiko lahko škodljivi. Najprej moramo razumeti, se na podlagi tega razumevanja sporazumeti in šele nato preračunavati, ali je mogoče naloge, ki jih postavljamo pred SV, ter naše ambicije in pričakovanja mednarodne skupnosti, predvsem Nata in EU, uresničiti z bistveno manjšim obsegom obrambnih sil, kot to načrtujemo. Najprej je treba doseči miselni preskok glede kakovosti in organiziranosti, ambicije pa podpreti tudi z viri. Očitno potrebuje Slovenija še več lekcij učenja iz izkušenj, da bomo po več letih obstoja samostojne države zrelejši in samozavestnejši.

\section{OBRAMBNI IZDATKI}

Realni obrambni izdatki v svetu še vedno naraščajo kljub finančni in gospodarski krizi. Evropa pri tem precej zaostaja in s tem tvega svojo relevantnost, če ne celo varnost generacij, ki prihajajo in ki jih s takšnim ravnanjem lahko prikrajšamo za mir, ki ga mnogi na tem kontinentu uživajo od srede prejšnjega stoletja. Nekatere ugotovitve glede Nata so, da so ZDA svojo uporabnost in učinkovitost v primerjavi z evropskimi zaveznicami v desetih letih skoraj podvojile (s 40 odstotkov prispevka $\mathrm{v}$ zavezništvo na več kot 70). Mnogi se ponovno sprašujejo, zakaj morajo ameriški davkoplačevalci financirati obrambo in varnost Evropejcev, kot je to na primer izpostavil generalni sekretar Nata na sestanku obrambnih ministrov v Bruslju, marca 2011, ameriški obrambni sekretar pa na to opozoril tudi na zadnjem sestanku junija 2011.

Kar zadeva vire, ni treba posebej poudarjati, da brez zadostnih obrambnih virov uspešna in učinkovita transformacija ni mogoča. Zagotavljanje zadostnih finančnih virov in njihove ustrezne razvrstitve je temelj vseh naših naporov. Tu so trenutne težnje precej zaskrbljujoče, saj se odmikamo od načrtovanega skupnega števila in doseganja ciljnega razmerja izdatkov za osebje, operacije, vzdrževanje, opremo in infrastrukturo (razmerje $50: 30: 20$ ). Dolgoročno je nujno vzdrževati vsaj zmerno realno rast obrambnih izdatkov in se ogibati njihovemu morebitnemu padcu (Šavc, 2009).

Glede na zelo majhen delež finančnih sredstev v skupnih obrambnih izdatkih, ki jih RS namenja za nakupe in gradnjo, moramo izpostaviti, da brez zadostnega obsega obrambnih investicij ni novih zmogljivosti. Več slovenskih obrambnih ministrov je od začetkov poklicne vojske zagovarjalo »majhno, vendar moderno vojaško organizacijo«. Pojem moderna ni povezan samo z modernizacijo. Tehnološke spremembe se ne dogajajo samo na oborožitvenih sistemih, temveč tudi širše, predvsem pa na področjih poveljevanja in kontrole, na obveščevalnem področju ter v podpori. Rekli 
smo že, da obrambni viri v svetu in vojaške investicije v EU naraščajo z najmanj triodstotno realno rastjo, torej nad ravnijo povprečne inflacije.

Gospodarska kriza je močno prizadela gospodarstvo, RS je doživela (leta 2010) enega največjih padcev rasti BDP v območju evra. V obdobju do leta 2009 so se obrambni izdatki povečevali za povprečno 5,6 odstotka na leto. Povprečni delež BDP za obrambne izdatke v obdobju 2004-2009 je bil 1,5 odstotka BDP, kar je pod neformalno dogovorjenimi merili Nata - dva odstotka BDP. RS je med 27 članicami na 14. mestu glede na odstotek BDP za obrambne izdatke leta 2011. Namenja tudi enega najmanjših deležev sredstev za nakupe (v celotnih obrambnih izdatkih) v zavezništvu in je v skupini držav, ki temu segmentu namenjajo manj kot 10 odstotkov obrambnih izdatkov.

Ohranjanje finančnih sredstev za glavne nabave na sedanji (nizki) ravni v kratkoročno-srednjeročnem obdobju pomeni zgolj stagnacijo razvoja SV, v srednjeročno-dolgoročnem obdobju pa verjetno vodi v njeno popolno nazadovanje ali celo razkroj, saj področje modernizacije ne vključuje le nabav oborožitve in opreme za nove zmogljivosti, temveč tudi za ohranjanje in posodabljanje zmogljivosti ter njihovo uporabo v MOM. Menimo, da ne sme prevladati prepričanje, da lahko načrtovani razvoj SV zagotovimo s sedanjim obsegom finančnih virov oziroma celo z njegovim dodatnim zmanjšanjem.

ReSDPRO le na splošno, pa vendar še vedno dovolj jasno, opredeljuje dolgoročni cilj za doseganje neformalno dogovorjenega Natovega praga obrambnih izdatkov, in sicer dva odstotka BDP. Ni pa bolj določena v oprijemljivejši opredelitvi finančnih virov za doseganje razvojnih ciljev SV. Zadolžuje Vlado RS, da v okviru srednjeročnih programov zagotovi ustrezno višino sredstev za modernizacijo SV. S tem ji Državni zbor nalaga veliko odgovornost in hkrati omogoča veliko prostora za uresničitev ambicij. Nedvoumno pa moramo ugotoviti, da bosta razvoj in postavitev vseh zmogljivosti, ki jih RS načrtuje na podlagi sprejete ReSDPRO 2025, zahtevala povečanje obsega in ravni obrambnih izdatkov (ReSDPRO 2025, 2010).

\section{KADROVSKI VIRI}

Na področju kadrovskih virov prinaša večjo spremembo zmanjšanje skupnega obsega SV z dosedanjih 14.000 na 10.000 pripadnikov. To vključuje predvsem zmanjšanje načrtovane ravni stalne sestave z 8500 na največ 8000 pripadnikov ter pogodbene rezerve s 5500 na največ 2000 pripadnikov. Zmanjšanje samo po sebi sicer nima neposrednih negativnih posledic, saj načrtovane ravni stalne sestave nismo uspeli doseči (vaja s svinčnikom in radirko). V preteklem obdobju se je skupni obseg SV na ravni 14.000 vzdrževal predvsem z obvezno rezervo, ki pa se ni usposabljala in ni podpirala uvedbe ključnih zmogljivosti SV.

V letih od 2008 do 2010 je bil dosežen precejšen napredek pri zagotavljanju novih pripadnikov SV, kar je tudi posledica nove zakonodaje iz leta 2007 ter gospodarske 
krize in povečanja brezposelnosti. V prihodnjem načrtovalnem obdobju, še posebej po koncu gospodarske krize, bo treba poiskati in izvesti ukrepe, s katerimi se bo dosežena raven pripadnikov SV ohranjala ter hkrati zagotavljalo njeno dopolnjevanje z novimi kadri.

Izpostaviti je treba, da je v primerjavi z večino članic Nata status pripadnikov SV neprimeren, saj so izenačeni z javnimi uslužbenci. Prav tako sta delež in obseg civilnih oseb v celotnem obrambnem resorju precejšnja in zdi se, da glede na skupni obseg SV občutno preobsežna. Zaradi tega je na primer razmerje med vojaškimi in civilnimi osebami približno 5 : 1, kar pomeni 1400 civilnih oseb (tudi v SV) na dobrih 7000 vojaških (brez pogodbene rezerve). Popraviti ta razmerja bo izziv za vsako vlado in obrambnega ministra še vrsto let. Kadrovska neskladja je nemogoče rešiti preko noči, ostri rezi so nepopularni in v RS verjetno nestvarni, posledice pa neposredno vplivajo na nova prihodnja neskladja, ki bodo povzročala težave. Sistemske kadrovske težave bomo nosili s sabo v prihodnost, z njimi pa se bo ukvarjalo še več generacij.

\section{ORGANIZIRANOST SV IN MO NA STRATEŠKI RAVNI}

Eno ključnih vprašanj se nanaša na organiziranost SV in MO kot celote. Glavni izziv je zmanjšanje skupnega obsega organizacijskih enot (ravni vodenja in poveljevanja ter števila brigad v SV in skupnega obsega notranjih organizacijskih enot v upravnem delu MO) ter doseganje večje učinkovitosti z uveljavitvijo ene izmed predlaganih oblik integracije civilnega in vojaškega dela (SPOR, 2009; Mikuž, 2010, str. 57-59).

Pozitivno moramo sprejeti doseženo stanje v okviru notranje konsolidacije SV ter sprememb, ki jih prinašata nova sistemizacija in notranja organizacija MO. S tem je bil dosežen napredek v razmerju med častniki, podčastniki in vojaki, ki je povečal operativni del SV, ter v zmanjšanju skupnega števila notranjih organizacijskih enot upravnega dela, ki je z zmanjšanjem števila zaposlenih pozitivno prispeval k skupnemu skrčenju sredstev za kadre. A priznajmo si iskreno, da smo na takih razmerjih nekajkrat že bili in da so aktualni ukrepi v obrambnem resorju ustavili, pa tudi odpravili nekatere nepravilnosti, povzročene v preteklih obdobjih, še zdaleč pa niso resnično racionalizirali obrambne administracije (zdi se, da je prevelika tako $\mathrm{v}$ SV kot v civilno-upravnem delu MO), ki bi jo morali že davno.

Naslednji velik korak je integracija civilnega in vojaškega dela MO, ki jo opredeljuje in določa tudi ReSDPRO 2025. Vse do sprejetja politične odločitve ter njene uveljavitve $\mathrm{z}$ ustreznimi normativnimi akti (nujna je sprememba zakona o obrambi $\mathrm{v}$ določilih o Generalštabu SV) bo nerešeno tudi vprašanje ravni vodenja in poveljevanja v SV, ki je neločljivo povezana s strateško (ne)integracijo civilnega in vojaškega dela MO.

S tem bi obvladovali številčnost in celovitost nalog ter političnih ciljev (ki jih določajo sodobni izzivi) obrambnega resorja, ki zahtevajo uporabo različnih instrumentov 
države in vključujejo usklajevanje že v procesu presoje, načrtovanja in izvedbe $\mathrm{z}$ medresorsko delovno kulturo razumevanja ter strukturo in zaupanjem (Mikuž, 2010, str. 56).

\section{PREDNOSTNE ZMOGLJIVOSTI, KI IZHAJAJO IZ RESOLUCIJE O SDPRO 2025, IN NATOVA ANALIZA NJIHOVE UVELJAVITVE}

Kljub doseženemu uspehu v obdobju do leta 2009 so številni rebalansi in zaradi njih veliko znižanje obsega in ravni obrambnih izdatkov zelo negativno vplivali na nadaljnji razvoj SV in oblikovanje njenih prednostnih zmogljivosti. Zaradi tega bo prišlo do nekajletnega zamika skoraj pri vseh preostalih zmogljivostih z Natovega seznama ciljev sil 2008, kar že v izhodišču onemogoča doseganje povezljivosti skladno z imperativom ciljev sil Nata, pa tudi EU in stalnega evropskega strukturnega sodelovanja (Permanent European Structural Cooperation - PESCO), ki ga v okviru SVOP opredeljuje Lizbonska pogodba.

\subsection{Kopenske zmogljivosti}

Premestljive sile so še vedno manjši del vseh sil kopenske komponente SV, čeprav se ta nenehno povečuje. Gorski bataljon, tankovski, artilerijski ter logistični bataljon in bataljon zračne obrambe so kot celota nepremestljivi, le z delom svojih zmogljivosti lahko podprejo premestljive zmogljivosti.

Artilerija ostaja nepremestljiva, kar je še vedno ena ključnih pomanjkljivosti SV. Pomenljiva je tudi informacija, da v obdobju do leta 2016 niso predvidena sredstva za nakup novega artilerijskega sistema.

Slovenija pravilno nadaljuje tudi razvoj bataljona za zbiranje obveščevalnih podatkov, identifikacijo ciljev in izvidovanje iz zraka (Inteligence Surveillance, Targeting and Air Reconnisance - ISTAR), ki bo kot celota prav tako (ne ravno pravilno ali primerno) nepremestljiv. Krčenje obrambnih sredstev je povzročilo zamik pri oblikovanju dveh osnovnih premestljivih zmogljivostih te enote, in sicer lahke izvidniške čete (po letu 2016) in brezpilotnih letal (po letu 2018).

Omejena ostaja tudi mobilnost enot na bojišču. Opuščeni so bili načrti za nakup dodatnih inženirskih mostov, precej šibko pa je tudi skupno usposabljanje kopenskih enot in helikopterjev (vertikalni manever).

Precej pozornosti bo treba nameniti prihodnjemu razvoju ustrezne logistične podpore v operacijah, da bo lahko učinkovito podpirala premestljivo bojno skupino.

Ključna zmogljivosti prihodnjega razvoja SV bo srednja bataljonska bojna zmogljivost, katere glavna oborožitev so oklepni transporterji 8 x 8. Srednja bataljonska bojna skupina je odločilnega pomena za prihodnji razvoj in transformacijo SV, med drugim tudi zaradi uvajanja novih tehnologij in konceptov delovanja. Zahtevnost 
oblikovanja in razvoja te zmogljivosti je tudi $\mathrm{v}$ tem, da ne temelji izključno na oblikovanju srednjega bataljona, temveč tudi na ustrezni povezavi vseh potrebnih elementov bojne podpore (inženirstvo, posredna in neposredna ognjena podpora, jedrsko-kemično-biološka-obramba - JRKBO ipd.) ter elementov za zagotovitev delovanja (logistična podpora, medicinska podpora, ISTAR, omrežne zmogljivosti itn.), ki to enoto dopolnjujejo in z njo oblikujejo enotno zmogljivost.

Oklepno bojno vozilo pehote 8 x 8 z ustrezno oborožitvijo (le šest topov kalibra 30 mm je bilo v zavezništvu razumljenih kot jasno politično sporočilo Slovenije, da nima ambicij in se noče udeležiti bojnih aktivnosti višje bojne intenzivnosti, bodisi $\mathrm{v}$ okviru nacionalne in kolektivne obrambe bodisi v operacijah kriznega upravljanja) bo SV omogočilo tisti minimum bojne moči, ki bo še opredeljeval njen bojni značaj in ji zagotavljal vojaško verodostojnost. Vsako zmanjševanje te ambicije bi ji odvzelo osnovno orodje za izpolnjevanje njenega poslanstva. Prevelika omejenost v spektru izvajanja nalog zaradi neprilagodljivosti z vidika bojnega delovanja bi jo marginalizirala tako znotraj zavezništva kot v SVOP EU. Verjetno pa bi izgubila relevantnost $\mathrm{z}$ vidika osrednjega jedra in stebra $\mathrm{v}$ okviru nacionalne obrambe in postavilo bi se vprašanje o smiselnosti drugih vlaganj, tako finančnih kot tudi kadrovskih.

Trenutno težave s projektom 8 x 8 ne povzročajo le stagnacije SV, temveč zadržujejo celotno obrambno načrtovanje, saj proces prehoda iz dolgoročnega v srednjeročni obrambni program stoji ter čaka politično odločitev o usodi trenutno podpisane pogodbe. Govorimo o najvišji prioriteti, kot jo je potrdil DZ, spremembe prioritet ter z njimi tesno povezana dinamika modernizacije vojske pa brez ključnih odločitev niso mogoče.

\subsection{Zračne zmogljivosti}

Izjemno pomembno je, da je DZ naposled le sprejel jasno politično odločitev, da Slovenija ne bo imela svojih nadzvočnih prestrezniških letal in da bo rešitev zagotavljanja te zmogljivosti za nadzor svojega zračnega prostora iskala v okviru zavezništva. Nato spričo teh dejstev in razumne ter racionalne politične odločitve izpostavlja Slovenijo kot vzor v regiji in severnoatlantskem prostoru. Samostojnejša drža, ki bi vključevala nakup ali najem lastnih letal, bi bila brez vsakršnega dvoma tako draga, da bi popolnoma zavrla razvoj načrtovanih minimalnih osnovnih vojaških zmogljivosti. Zaradi navedenega RS tudi $\mathrm{v}$ prihodnosti ne sme podleči skušnjavi pobud $\mathrm{z}$ zelo različnim ozadjem (od reševanja nacionalne oborožitvene industrije do nacionalnih ambicij sosednjih držav), ki nerealno nizko ocenjujejo stroške postavitve te zmogljivosti, saj si takega sistema v življenjskem stroškovnem ciklu preprosto ne more privoščiti.

Ponovno bi bilo tudi treba opraviti razmislek o smiselnosti uporabe lastnih šolskih letal za usposabljanje sorazmerno majhnega števila pilotov ter razširiti iskanje mogočih rešitev za usposabljanje v tujini ali v mednarodnem sodelovanju. Nova ReSDPRO opredeljuje, da bomo viške šolskih letal izločili iz uporabe. Odločitev 
temelji na domnevi racionalizacije oziroma pocenitve usposabljanja pilotov, ki jih SV potrebuje oziroma jih bo potrebovala za letenje na svojih transportni plovilih.

Dejstvo je, da SV potrebuje helikopterje in tudi transportna letala. Za vertikalni manever ene čete s polno bojno opremo v enem naletu potrebuje SV vsaj še osem srednjih transportnih helikopterjev, če odštejemo medevac, imamo le tri. Torej jih je vsaj trikrat premalo in zagotovitev dodatnih plovil je zahteven dolgoročni cilj. Zmogljivost pa mora biti seveda v operativni uporabi kopenskih sil in jih dnevno neposredno podpirati pri njihovih nalogah. Danes ni več prostora in denarja za uresničevanje parcialnih ambicij po dragih vojaških platformah, ki ne spadajo v skupni koncept in so bolj ali manj namenjene same sebi. Značaj SV se bo z ustrezno uporabo helikopterjev dodatno spremenil, kar bo omogočeno tudi z njihovo uporabo v MOM in zaželeno v sklopu angažiranja lastnih sil. Mogoče je sicer tudi letenje za zaveznike in partnerje, ki bi bilo tudi toplo pozdravljeno, ne bi pa imelo pričakovanega transformacijskega učinka na kakovostno rast SV.

Kako bi lahko ocenili prioriteto nakupa transportnega letala oziroma dveh glede na jasno izražene potrebe po helikopterjih? Glede doseganja taktičnih operativnih zmogljivosti SV je ta nakup zagotovo v podrejenem položaju, gledano širše pa je morda prednostna zmogljivost, s katero bi se država lahko bolje odzivala na širše potrebe kriznega upravljanja v mednarodnem okolju. Spomnimo se nakupa razkošnega falcona. Če bi takrat kupili veliko ptico, v katero je mogoče vgraditi VIP-salon, a hkrati prevažati četo SV ali zavidljivo količino tovora, bi bili danes operativnejši in relevantnejši. Trenutkov, ko smo rabili letalo za pomoč drugim, za prevoz svoje vojske ali za prevoz političnega vrha, se ne da popisati, prav tako tudi ne stopnje in cene tveganja, ki ga ob pomanjkanju te zmogljivosti nosimo.

\subsection{Pomorske zmogljivosti}

SV nadaljuje razvoj svoje pomorske komponente, čeprav spričo majhnosti akvatorija in obkroženosti z zaveznicami, ki imajo precej številčne in kakovostne zmogljivosti, to morda ni najbolj racionalno. Zagotovo pa ni potrebe po bojnih zmogljivostih na morju. Da pa so te zmogljivosti uporabne in koristne v širšem kontekstu in dobro služijo drugim, nevojaškim potrebam države, ni dvoma. Torej SV zagotavlja opravljanje nekaterih nalog na morju, ki v bistvu niso njeno poslanstvo. Obrambni proračun pravzaprav za državo financira in podpira nujno ali vsaj koristno in potrebno službo v njenih vodah. Od tod ravno v obrambnem resorju pobude o drugačnem organiziranju služb na morju in večkratne pobude o oblikovanju enovite službe, ki se lahko poimenuje tudi obalna straža, po vzoru primerljivih služb iz tujine. Naloge, ki jih pomorska komponenta SV opravlja, so večinoma naloge obalne straže in v nobenem primeru mornarice. Ker ni nadaljnjega medresorskega napora ter politične volje za koordinacijo vseh sedanjih služb na morju, nova ReSDPRO zgolj nedoločno opredeljuje, da je SV pripravljena združiti svoje pomorske zmogljivosti v prihodnjo, bolj integrirano pomorsko zmogljivost Slovenije za opravljanje nalog na morju. Drznemo si zapisati, da bo Slovenija slej ko prej stopila na pot učinkovitejše organiziranosti svojih institucij na morju ali celo združila vse zmogljivosti in morda tudi službe pod 
skupno streho, iz česar bo nastala tudi obalna straža. Nato takšno evolucijo podpira že deset let in v svojih rednih analizah pregleda obrambe Slovenije ni nikoli izpustil odstavka, da je patruljni čoln Ankaran anomalija v razvoju SV. Precej presenečenja oziroma, če smo odkriti, osuplosti je bilo videti na obrazih Natovih analitikov iz Bruslja, ko so ugotovili, da smo si zagotovili še večje plovilo. Zavezništvo ne oporeka zadovoljevanju potreb države na njenem ozemlju in v akvatoriju, seveda pa imajo lahko upravičene pripombe na prioriteto razvoja ključnih bojnih zmogljivosti SV. Po naši oceni bi bilo treba rešitev iskati v že omenjeni integraciji vseh resorjev in njihovih zmogljivosti ter poglobljenem sodelovanju (tudi institucionalnem) s sosednjima pomorskima državama ter tudi širše v regiji. Če bi nam z združevanjem in delitvijo nacionalnih pomorskih zmogljivosti uspelo oblikovati skupno vizijo večnacionalne obalne straže na Jadranu, bi bil to ne samo najbolj racionalen projekt, temveč hkrati tudi nenadomestljiv mehanizem varnosti in zaupanja med državami, $\mathrm{s}$ katerimi si delimo Jadransko morje. To morje je vsem in vsakomur posebej strateški interes, ki se ne more meriti s površino vode, ki pripada posamezni državi ob njem.

\section{SODELOVANJE V MEDNARODNIH OPERACIJAH IN NA MISIJAH TER UPORABNOST SIL}

Dolgo pot smo morali prehoditi do zavedanja, da je sodelovanje SV v MOM prikaz zaščite nacionalnih interesov. To je zaenkrat razvidno $z$ izpostavljanjem zunanje politike na Zahodnem Balkanu, kjer delujejo tudi največji kontingenti in posamezniki SV v vseh oblikah, na vseh ravneh ter v sklopu tako Nata kot EU.

RS kljub negativnim posledicam gospodarske in finančne krize še vedno zagotavlja sorazmerno velik prispevek v MOM. Zdi se, da bi lahko na tem področju kaj prihranili, vendar moramo vedeti, da gre večinoma za angažiranje v operacijah nižje bojne intenzivnosti (če izvzamemo Isaf) in da je to operativno delovanje namenjeno tudi opravičevanju legitimnosti vojske ter hkrati zapolnjevanju njene smiselne zaposlitve. Po drugi strani je takšno angažiranje pomembno tudi v luči izkazovanja politične solidarnosti v mednarodni skupnosti. Kar pa pogrešamo, predvsem glede implikacij tega delovanja na SV, je tako imenovani transformacijski učinek, ki zaradi zadržanosti bolj ambicioznih operacij ostaja omejen.

Na področju kazalnikov uporabnosti sil (tj. deleža premestljivih in vzdržljivih sil) RS še vedno ne dosega Natovih meril (50 in 10 odstotkov), vendar se kljub temu delež uporabnih sil vsako leto povečuje. Pozitivno moramo oceniti sedanji in načrtovani obseg zmogljivosti v različnih operacijah Nata, še posebej v okviru NRF, v katerih SV sodeluje $z$ vedno večjimi zmogljivostmi ter z zmogljivostmi, ki presegajo zgolj nacionalne potrebe (na primer bataljon JRKBO).

Eno izmed vprašanj, ki se nenehno pojavlja v ozadju javne razprave, je, zakaj toliko premestljivih sil in zakaj toliko delovanja v MOM, saj to ne prispeva k nacionalni obrambi. Vendar bo prav nasprotno res, zgodovina nas namreč uči, da so vojne prihodnosti vedno drugačne od preteklih konfliktov in tudi naših pričakovanj. Kdor se 
najbolje prilagaja, ima v naravi najboljše možnosti preživetja. Kje se lahko bolje pripraviš na hibridne grožnje kot v okviru MOM ali na visoko tehnologijo kot v sodelovanju s silami, ki jo premorejo, in na delovanje skupaj z zavezniki, s katerimi deliš sistem kolektivne obrambe. Pridobljeno znanje in izkušnje neposredno služijo pripravljenosti na nacionalno obrambo in jo krepijo, in sicer mnogo bolj, kot si bi si lahko nepoučeni mislili, celo na višjo sposobnost delovanja v sistemu varstva pred naravnimi in drugimi nesrečami.

Menimo, da je trenutna ambicija okoli 500 pripadnikov v MOM, v težjih in najslabših primerih pa naj bi dosegla celo vzdrževanje srednje bataljonske bojne skupine (okrog 1200 pripadnikov) za eno leto, kot smo to zapisali v ReSDPRO, ustrezna, potrebna in ključna kot element verodostojnosti in relevantnosti sil, ki jih vzdržujemo. Mogoče manjka drznejše vključevanje v zahtevnejše operacije, pa bi bilo to področje lepo zaokroženo. Tudi čas za to še prihaja.

Sklep Ob zmerni, realni, a konstantni rasti obrambnih izdatkov bomo sposobni razvijati sodobno vojsko, ki ne bo le vedno bolj bojno sposobna, uporabna in vzdržljiva, temveč bo tudi ponos svojim državljanom in davkoplačevalcem. Nobena država do zdaj oboroženim silam ni odrekla primarne naloge, namreč pripravljenosti za klasične vojaške spopade (Mikuž, 2010, stran 50). Izurjena, motivirana, primerno opremljena in prilagodljiva sestava pomeni verodostojno vojaško silo, ki zna delovati doma in v vsakem okolju, skupaj z zavezniki pa tudi daleč od meja svoje domovine, če bo treba. SV se bo sposobna boriti tako doma kot v tujini, v okviru mandata ZN ali kolektivne obrambe po 5. členu Washingtonske pogodbe Severnoatlantskega zavezništva. $Z$ ramo ob rami $z$ zavezniki bo preživela na bojišču in skupaj $z$ njimi tudi zmagala. Tudi general Šteiner je že 19. maja 2008 vojaškemu odboru Evropske unije v Šmarjeških Toplicah dejal: »Nov obrambni značaj postavlja različne zahteve graditve vojaških zmogljivosti sil, ki morajo biti zmogljivejše, usmerjene k še večji učinkovitosti in sposobne izvajati ekspedicijske operacije v združenih medzvrstnih in medrodovskih silah.« Takšno vojsko si Slovenija želi in njeni državljani si jo tudi zaslužijo. Nova ReSDPRO SV jo ustrezno opredeljuje, nalog in izzivov v njeni uveljavitvi pa je še mnogo. Srečno ob dvajsetletnici Slovenska vojska in veliko vetra V tvoja (naša) jadra!

1. Celostne politične smernice 2006 (Comprehensive Political Guidance-CPG), 29. 11. 2006. http://www.nato.int/docu/basictxt/b061129e.htm, 17. 7. 2009.

2. Nato Handbook, 2006. Brussels: Public Diplomacy Division NATO. http://www.nato.int/ docu/handbook/2006/hb-en-2006.pdf, 17. 7. 2009.

3. Resolucija o strategiji nacionalne varnosti Republike Slovenije 2010, Uradni list RS, št. 27/2010 z dne 2. 4. 2010, Ljubljana.

4. Resolucija o splošnem dolgoročnem programu razvoja in opremljanja Slovenske vojske do leta 2025, Uradni list RS, št. 99/2010 z dne 7. 12. 2010, Ljubljana.

5. Resolucija o splošnem dolgoročnem programu razvoja in opremljanja Slovenske vojske, Uradni list RS, št. 89/2004 z dne 12. 8. 2004, Ljubljana. 
6. Splošni dolgoročni program razvoja in opremljanja Slovenske vojske, Uradni list RS, št. 97/2001 z dne 4. 12. 2004, Ljubljana.

7. Severnoatlantski sporazum (The North Atlantic Treaty/Washington Treaty), 4. april 1949, Washington. http://www.nato.int/docu/basictxt/treaty.htm, 17. 7. 2009.

8. Strateški koncept zavezništva (The Alliance's Strategic Concept), 28. in 29. maj 1991, Rim. http://www.nato.int/docu/comm/49-95/c911107a.htm, 17. 7. 2009.

9. Strateški koncept zavezništva (The Alliance's Strategic Concept), 23. in 25. april 1999, Washington. http://www.nato.int/docu/comm.htm, 17. 7. 2009.

10. Strateški koncept zavezništva (The Alliance's Strategic Concept), 23. in 25. november 2010, Lizbona. http://www.nato.int/docu/comm.htm, 17. 7. 2009.

11. Strateški pregled obrambnega resorja 2009, Povzetek ključnih ugotovitev SPOR 2009 za komuniciranje z zainteresiranimi javnostmi http://www.mo.gov.si/fileadmin/mo.gov.si/ pageuploads/pdf/ministrstvo/SPOR2009.pd, 14. 4. 2011.

12. Mikuž, Ivan, 2010. Civilno-vojaški vmesnik. Bilten Slovenske vojske, December 2010-12/ št. 4, Ljubljana.

13. Humar, David, 2010. Vključevanje Slovenske vojske v Nato in vojaško strukturo Evropske unije. Bilten Slovenske vojske, November 2009-11/št. 3, Ljubljana.

14. Šavc, Primož, 2009. Slovenske izkušnje pri obrambnem planiranju ob peti obletnici članstva v Natu na področju obrambnega planiranja. Bilten Slovenske vojske, November 2009-11/st. 3, Ljubljana. 